\title{
Testimonios mayas durante el conflicto armado interno en Guatemala
}

\author{
MORNA MACLEOD
}

Se analizan testimonios de activistas mayas durante el conflicto armado en Guatemala, vertidos en el Tribunal Permanente de los Pueblos, respaldados con otras fuentes, en especial la revista Polémica, de Costa Rica. Poco se ha escrito sobre testimonios emitidos durante la guerra: ¿qué características, potenciales y constreñimientos tiene la denuncia de atrocidades en tiempo real? Después de analizar testimonios y comunicaciones actuales con los actores, argumento que testificar en la guerra recobra agencia, urgencia para salvar vidas y aporta fuerza política a la literatura de la memoria. Sugiero que las voces mayas enriquecen los testimonios-denuncia del Tribunal al incluir otras reivindicaciones, pero lo que se retoma y omite de ellos teje otras violencias silenciadas.

PALABRAS CLAVE: testimonio, mayas, conflicto armado interno, Guatemala, denuncia

\section{Mayan Testimonies during Guatemala's Internal Armed Conflict}

I analyze various testimonies presented by Mayans during the armed conflict in Guatemala in the international arena: The Permanent Peoples' Tribunal, endorsed with other sources, particularly the journal Polémica, from Costa Rica. Surprisingly little has been written on testimony during war: what characteristics, potentials and restraints do these testimonies have? Through analyzing testimonies and personal communication with those involved in the Tribunal, I argue that testifying in war heightens agency and an urgency to save lives that give political clout to the literature on memory. I suggest that the voices of Mayans from Guatemala enrich the Tribunal's testimonydenunciations, but what is included and omitted from their testimonies weaves other silenced forms of violence. 


\section{Introducción}

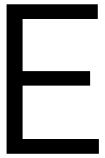

s sorprendente que haya una vasta producción teórica sobre los testimonios

después de guerras, dictaduras militares y conflictos armados internos, como los estudios del Holocausto, la justicia transicional y la literatura (auto)biográfica, y en contraste, que la teorización de testimonios producidos durante estos periodos de crisis sea escasa. En este artículo analizo cómo el hecho de atestiguar en foros públicos permitió a algunos hombres y mujeres mayas transmitir sus vivencias y hacer un llamado a poner fin a las masacres y la estrategia de Tierra Arrasada ${ }^{1}$ en momentos cúspide de las políticas contrainsurgentes en las zonas rurales del altiplano durante el conflicto armado en Guatemala (1982-1983). ${ }^{2}$ Los testimonios se entregaron al Tribunal Permanente de los Pueblos (TPP), Sesión Guatemala, ${ }^{3}$ llevado a cabo en Madrid, en enero de 1983, y a la revista Polémica, que incluía un apartado testimonial. ${ }^{4}$ Estos testimonios, caracterizados por su urgencia e inmediatez, representan un parteaguas. A partir de entonces, mujeres y hombres mayas empiezan a tener

1 El informe de la Comisión de Esclarecimiento Histórico (CEH) registró 626 masacres, la mayoría en el altiplano indígena y 440 aldeas arrasadas. Un total de 42275 casos identificados con nombre fueron documentados por la CEH, 6159 fueron víctimas de desaparición forzada y 23671 ejecuciones extrajudiciales. La Comisión estimó que entre medio millón y un millón y medio de personas fueron desplazadas en Guatemala o cruzando fronteras, en especial con México (1999b: 211-212). De los casos documentados por esta comisión de verdad, 83\% fue de indígenas mayas.

2 Para una visión exhaustiva de la violación a los derechos humanos, véase CEH (1999a).

3 Los tribunales de conciencia, organizados por figuras públicas y organizaciones de la sociedad civil, buscan ejemplificar cómo debería funcionar el sistema de justicia en contextos de impunidad y violaciones masivas a los derechos humanos. El tPp ha sesionado más de 40 veces desde su comienzo, en 1979.

$4 \quad$ La revista Polémica fue fundada a principios de la década de 1980 por Edelberto Torres Rivas y Gabriel Aguilera Peralta, académicos guatemaltecos exiliados en Costa Rica. Fue un espacio de análisis sobre Centroamérica durante los conflictos armados en la región. 
voz y agencia en los espacios internacionales para denunciar la violencia atroz del Estado y el ejército contra las comunidades indígenas. Aquí, al complejizar la noción de testimoniar, desvelo varios momentos de este proceso.

Primero, hago una reflexión teórica sobre las genealogías y tratamientos en torno al testimonio, su sentir polisémico y sus usos múltiples, con acento en Latinoamérica. A partir de 1983, sobre todo en el TPP, emergen actores mayas que atestiguan lo que ocurre en sus comunidades. Los testimonios representan reclamos colectivos, agravios recientes e históricos, a menudo acompañados por un llamado a luchar por una vida digna, justa y respetuosa de su cultura. El acto de atestiguar representa un salto cualitativo, pues antes eran terceros quienes denunciaban la aguda represión contra las comunidades mayas. Sin embargo, testificar en persona implica silencios y omisiones, sobre todo a la hora de la edición y publicación de los testimonios.

Al narrar esta historia del TPP en Madrid, sugiero que constituyó un punto de inflexión en la historia reciente y la memoria colectiva, por el protagonismo de personas mayas en espacios de denuncia internacional. A pesar de haber caído casi en el olvido, intento demostrar que la Sesión Guatemala fue crucial para dar a conocer las atrocidades que sucedían en ese país y sirvió como herramienta de legitimación del trabajo de denuncia e incidencia en el ámbito internacional, lo que contribuyó a la condena del Estado guatemalteco por crímenes de lesa humanidad.

Aunque no viví el TPP en persona, colaboré en la Ciudad de México con la Comisión de Derechos Humanos de Guatemala (CDHG), impulsora del evento, desde finales de 1983 hasta comienzos de 1986. Mi proceso de inmersión en lo concerniente al conflicto armado y las atrocidades cometidas en Guatemala estuvo permeado por muchas personas que participaron en el TPP, que marcaron de alguna manera mi historia. Mi ruta metodológica consistió en analizar los testimonios escritos en el libro del TPP y la revista Polémica, y contextualizarlos con conversaciones y correspondencia escrita de luchadores sociales y académicos de la época. ${ }^{5}$ Conocerlos desde aquellos tiempos facilitó entrar en contacto de nuevo con ellos y que compartieran pormenores que quizá no hubieran mencionado a una investigadora desconocida. También pude constatar que la gente rememora de forma diferente y la verificación de hechos es necesaria.

\section{La emergencia del testimonio en el siglo $x x$}

Hugo Achugar (2002) y Michal Givoni (2011) señalan que el testimonio y el acto de atestiguar tienen una larga trayectoria y se remontan a la época de los griegos y romanos. Sin embargo, el testimonio como lo conocemos hoy, y su gran diversidad, emerge en el siglo Xx. Sus raíces datan de la Gran Guerra, pero es luego de la Segunda Guerra Mundial cuando alcanza su apogeo. Abundan los testimonios de carácter literario, epistolar y (auto)biográfico sobre la Primera Guerra Mundial. ${ }^{6}$ Los primeros poemas nacionalistas —el más emblemático, El soldado, de

Agradezco a Gabriel Ixmatá, quien me hizo ver la importancia del TPP en largas conversaciones; a Aída María Noval por compartirme el libro del TPP; a Anantonia Reyes por sus amplios conocimientos y contactos en torno a los derechos humanos en Guatemala; a Raúl Molina y Arturo Taracena por sus respuestas escritas sobre el tpp en el contexto del conflicto armado; a Pablo Ceto y al ex secretario general de la radiodifusora Voz de Atitlán por sus conversaciones telefónicas para analizar sus propios testimonios presentados, y a Marta Casáus y Manolo García por su apoyo y análisis.

$6 \quad$ La Comisión Internacional de la Cruz Roja jugó un papel relevante durante la Primera Guerra Mundial, con apoyo humanitario, informes y fichas de los presos de guerra, aunque no recogió testimonios. Véase ICRC (2005). 
Rupert Brooke- dieron paso a los war poets británicos que vivieron los horrores de las trincheras, entre ellos, Wilfred Owen - muerto en combate a los 25 años de edad- y Siegfried Sassoon. El Himno para los jóvenes condenados, en el que Owen captura la brutalidad bélica deshumanizante, es representativo:

¿Qué campanas doblan para los que mueren como bestias?

Sólo la ira monstruosa de los disparos.

Sólo el rápido tableteo tartamudo de los rifles puede vomitar sus plegarias apresuradas (Ridao, 2012).

Hay también una amplia producción de (auto) biografias y novelas después de la guerra, como la conocida Sin novedad en el frente, del escritor germanoestadounidense Erich Maria Remarque (1929). Centenares de cartas personales se convirtieron en material de archivo, aunque no fueron concebidas con esta intención. Sin nombrarla como tal, Givoni afirma que:

La era del testimonio empezó con la Primera Guerra Mundial y llegó a su apoteosis con la acción humanitaria y el activismo por los derechos humanos al final de la Guerra Fría. La Gran Guerra generó un diluvio de escritos de veteranos que convirtió el testimonio en un fenómeno colectivo y lo marcó como un género literario nuevo (2011: 158). ${ }^{7}$

La categoría de testimonio se popularizó años después de la Segunda Guerra Mundial, con los estudios del Holocausto (Levi, 1989; Arendt, 1970; Wieviorka, 2006; Pollak, 2006; Agamben, 2000). Primo Levi fue de los primeros en escribir sobre su experiencia en Auschwitz, con Se questo é un uomo, en 1947 (1989), dos años después del final de la Segunda Guerra Mundial.

La "era del testigo", término muy difundido, acuñado por Annette Wieviorka (2006), refleja la explosión de testimonios escritos después de la Segunda Guerra Mundial, con los estudios del Holocausto de los judíos exterminados en campos de concentración y silencios en torno a los comunistas, miembros de la resistencia, homosexuales y gitanos, también masacrados ahí. Shoshana Felman (2000) sitúa el juicio del alto funcionario nazi Adolf Eichmann en Jerusalén, en 1961, como el punto de inflexión que proveyó autoridad semántica a las víctimas. Dialoga con Hannah Arendt (2013) y reconoce que "la justicia para Arendt es una experiencia conceptual minuciosamente ascética y disciplinada, no un escenario emocional para la expresión espectacular pública” (Felman, 2000: 490). En cambio, Felman resalta el potencial de lo performativo, tanto en el juicio de Eichmann, como en las famosas palabras j'accuse del escritor francés Émile Zola (1898), cuando denuncia el antisemitismo y la injusticia en el caso Dreyfus. ${ }^{8}$ La denuncia pública de "J'accuse" tiene un vínculo estrecho con los testimonios durante los sucesos, al "confrontar el poder” (Givoni, 2011: 149) y responsabilizar al Estado por contextos de injusticia y extrema violencia política (Manfredi, 2018).

Atestiguar sobre hechos traumáticos requiere una escucha empática, en la que quien escucha se convierte en parte del proceso de dar testimonio (Laub, 1992). Caroline Wake (2008: 188) sugiere que quienes escuchan también se convierten en testigos. Esto es en particular relevante para los tribunales de conciencia, como el TPP.

\footnotetext{
$7 \quad$ La traducción es mía.

8 En 1894, el capitán Alfred Dreyfus fue sentenciado a cadena perpetua en Francia bajo la falsa acusación de haber compartido secretos militares con los alemanes. La denuncia pública de Zola durante el proceso le obligó a huir a Inglaterra luego de la emisión de una orden de aprehensión en su contra.
} 


\section{El testimonio como género polisémico y polivalente}

Es preciso señalar que los testimonios en general, aunque no siempre, son contranarrativas de actores sociales subalternos y sus aliados que interpelan al poder. El quehacer fundamental del testimonio es comunicar o denunciar, incitar una respuesta de su audiencia. El testimonio reclama una escucha empática, un reconocimiento del agravio y una llamada a la justicia social. La mayoría denuncia; algunos relatan luchas sociales y estilos de vida contrahegemónicos, como en el caso de los pueblos indígenas. Tienden a ser de carácter colectivo, enunciados por personas específicas. John Beverley (2002a) resalta que implican un sentido de autoridad, por haber presenciado de manera directa o indirecta la experiencia narrada. Los testimonios del último medio siglo se nutren de varias disciplinas: antropología, literatura, historia, sociología, política, psicología, psicoanálisis y periodismo (Jelin, 2002; Acedo, 2017), así como de los estudios culturales, la memoria, el Holocausto y la justicia transicional. A menudo tienen carácter interdisciplinario, híbrido, y es difícil asignarles categorías.

Una de las disputas prevalentes ha sido el estatus del testimonio. Los historiadores tienden a verlo con cierta desconfianza por su "falta de rigurosidad" y lo relegan al lugar de materia prima de archivo (Hobsbawm, 1998). En cambio, psicoanalistas como Dori Laub (1992) priorizan su significado por encima de los datos duros. Enzo Traverso resalta lo entrelazadas que están la historia y la memoria del pasado reciente, porque a menudo los historiadores vivieron los hechos "como actor y como testigo" (2016: 19). Alessandro Portelli (1989) nos recuerda que la gente atestigua y recuerda de formas muy diversas. De hecho, en la elaboración de este artículo fue fascinante contactar a varios de los actores directos e indirectos del TPP Sesión Guatemala. Cada persona entrevistada abrió vetas nuevas, con ciertos lapsus en su memoria que tuve que verificar. Así descubrí, por ejemplo, que ya había una delegación de profesionales guatemaltecos ante la Organización de las Naciones Unidas (ONU) para denunciar las violaciones a los derechos humanos en su país en 1982, incluso en 1962 hubo un informe temprano de denuncia de la represión de la Asociación de Estudiantes Universitarios (AEU), enviado a la Comisión Interamericana de Derechos Humanos (Reyes y Del Valle, 2013). Algunos testigos del TPP mencionaron a otros que en realidad no estuvieron.

Además de las inconsistencias en las memorias individuales, otro tema que atraviesa los testimonios es el silencio. ¿Qué se puede decir y qué es indecible? Porque los verdaderos testigos están muertos (Levi, 2004; Agamben, 2000). Los silencios también pueden deberse a "huecos traumáticos" (Jelin, 2002) o hechos tan dolorosos que no pueden nombrarse o no encuentran escucha. Los testimonios en las comisiones de verdad y juicios en tribunales suelen ser narrativas constreñidas; hay reglas implícitas sobre lo que no se puede decir, como haber participado en un movimiento revolucionario (Rodríguez, 2011), y explícitas, como no nombrar a los perpetradores y no tratar temas estructurales (Castillejo, 2007). Así, estos foros resaltan el papel de víctima de quienes atestiguan y les restan capacidad de agencia social.

\section{Genealogías y diversidad de testimonios en Latinoamérica}

El testimonio, en sus múltiples expresiones, recobra importancia fundamental en Latinoamérica, sobre todo a partir de la década de 1970. Lynn Stephen (2017) remite sus orígenes a los textos de los pueblos originarios antes de la Conquista, que realzan las luchas sociales y militares de figuras prehispánicas destacadas. Otra vertiente importante surge con la Revolución cubana. En 1959, a un año de su triunfo, 


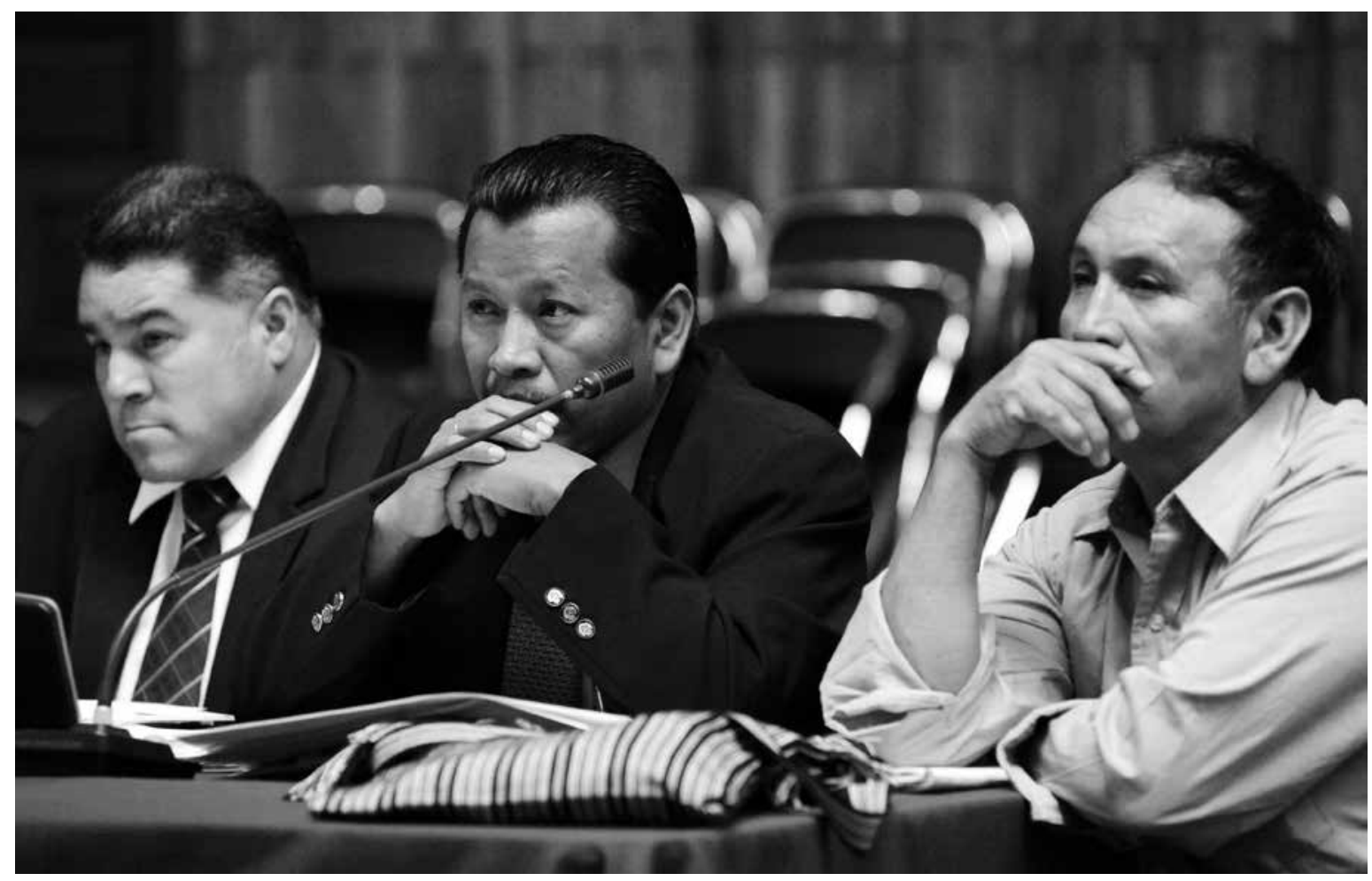

RICARDO RAMIREZ ARRIOLA $360^{\circ}$ 、 Querellantes adhesivos en el juicio contra el ex general y ex dictador Efraín Ríos Montt, acusado de genocidio y crímenes de lesa humanidad cometidos contra 1171 indígenas ixiles durante su gobierno de facto, entre el 23 de marzo de 1982 y el 8 de agosto de 1983 . Torre de Tribunales, Ciudad de Guatemala, Guatemala, 17 de abril de 2013.

se funda la Casa de las Américas, que en 1970 crea un premio anual para el género “Testimonio”. Los libros que resultan son testimoniales heroicos, centrados en personas y luchas revolucionarias, de acuerdo con los principios éticos de la Cuba revolucionaria. En ellos no hay espacio para la vulnerabilidad humana. Otras vertientes se refieren a la denuncia de atrocidades, de la violencia estructural, además de los llamados a la lucha social.

Algunos autores resaltan que constituyen expresiones de los subalternos, a menudo orales, que interpelan el poder y cuestionan la historia hegemónica. Los testimonios, tanto individuales como colectivos, abonan a la creación de la memoria histórica y el fortalecimiento de las luchas por la transformación social. Casi toda la reflexión teórica acerca de los testimonios se refiere al vasto corpus de literatura escrita después de guerras, dictaduras y conflictos armados. Se sitúan en el campo de disputa por la memoria (Jelin, 2002; Stern, 2000; Calveiro, 2006) y en el marco de la justicia transicional, las comisiones de verdad y los juicios a perpetradores. Además, hay una nutrida literatura biográfica, autobiográfica y de novelas testimoniales que reflejan la realidad política de sociedades en conflicto (Franco, 2002; Acedo, 2017).

Los testimonios durante los sucesos operan con otra lógica, contienen urgencia y desesperación ante la impotencia de lo que pasa en ese momento - la masacre de comunidades, la desaparición y asesinato de familiares, líderes y personas cercanas, la violación sexual, la tortura y la mutilación-y dirigen 
un llamado de ayuda al público para poner fin a estos horrores. Los testimoniantes son emisores y denunciantes. Hay dos perfiles de testigos directos: con y sin experiencia organizativa previa. Lo que los une es la desesperación e impotencia ante los acontecimientos en sus comunidades. Natalia de Marinis habla de las mujeres triqui que huyeron de su comunidad en guerra: "la desesperación por lo que sucedía en el pueblo las llevó a romper el miedo y el silencio y hablar desde un 'sentir', como ellas expresaron” (2013: 29). Son mujeres indígenas obligadas por las circunstancias a trascender su papel tradicional de género ante la angustia de lo que sucede. Los testimoniantes tratados en este artículo son actores sociales políticamente organizados, con experiencia, formación y rasgos de liderazgo, escogidos para atestiguar por su elocuencia y don de palabra.

Los actores sociales que dan testimonio con frecuencia proceden de experiencias y prácticas de la teología de la liberación y la pedagogía de los oprimidos de Freire (Yúdice, 2002). Ambas promueven la concientización y transformación de los oprimidos para convertirlos en sujetos protagónicos: "la concientización practicada por la pedagogía freireana y por la teología de la liberación proporciona otro modelo que no es exclusivamente epistemológico o ético sino ambos simultáneamente" (2002: 223); sus criterios de validación incluyen la "concientización, creación de solidaridad, solicitud de apoyo" (2002: 227).

Este acercamiento es el que mejor ayuda a comprender los testimonios de hombres y mujeres mayas en el TPP y otros espacios internacionales, en los peores años de genocidio, Tierra Arrasada y desplazamiento forzado. Por medio de la concientización, los testimonios no se reducen a la denuncia de las atrocidades y el papel de víctima. Unos se remiten a la violencia estructural, el racismo y la gran desigualdad en el país, varios llaman a la lucha social y revolucionaria, y algunos reivindican la dignificación de la cultura maya.

\section{El Tribunal Permanente de los Pueblos, Sesión Guatemala (1983)}

El Tribunal Internacional sobre Crímenes de Guerra, más conocido como el Tribunal Russell, de 1976, fue el primer tribunal ético o de conciencia. Organizado por Bertrand Russell, Jean Paul Sartre, Simone de Beauvoir, Julio Cortázar y Lelio Basso, entre otros, investigó y evaluó la intervención estadounidense en Vietnam. A partir de 1979, la estrategia fue impulsada por el jurista y senador Basso en Italia, con la creación del TPP, para analizar y condenar violaciones a los derechos humanos, con énfasis en los derechos de soberanía y autodeterminación de los pueblos. Hasta 2018, el TPP había sostenido 44 sesiones sobre temas diversos: conflictos armados, impunidad, genocidio, políticas económicas, corporaciones transnacionales y devastación ambiental en numerosos países y continentes.

El primer tribunal internacional de conciencia sobre la represión política y extrema violencia en Guatemala tuvo lugar en Madrid, del 27 al 31 de enero de 1983. El propósito central fue analizar y condenar las atrocidades del régimen del general Efraín Ríos Montt tras el golpe de Estado del 23 de marzo de 1982. El TPP fue respaldado por la CDHG. El Instituto de Estudios Políticos para América Latina y África (IEPALA) fue la secretaría ejecutiva del Tribunal y publicó el libro del TPP caso Guatemala en enero de 1984. El TPP tuvo un jurado de 15 personajes connotados, la mayoría académicos prestigiosos de Europa, Estados Unidos, Latinoamérica y el Caribe. Además, participaron el escritor Eduardo Galeano, el obispo mexicano monseñor Sergio Méndez Arceo y dos premios Nobel, George Wald, de Estados Unidos, y Adolfo Pérez Esquivel, de Argentina. El TPP también tuvo un Comité de Honor, compuesto en su mayoría por hombres mestizos guatemaltecos.

La petición inicial de la CDHG mencionó la violación sistemática a los derechos humanos. Se 
presentaron 14 informes de expertos y 22 testimonios. Estos últimos eran de siete hombres y dos mujeres mayas, tres mujeres y siete hombres mestizos, y tres hombres extranjeros que habían estado en Guatemala. El TPP gozó de un alto perfil político y el evento fue inaugurado por el alcalde de Madrid.

El país se encontraba en los peores años de políticas de exterminio: ejecuciones y desapariciones forzadas, masacres y Tierra Arrasada en comunidades indígenas. La colaboración entre la Unidad Revolucionaria Nacional Guatemalteca (URNG), reciente coalición insurgente, y el TPP en Madrid fue un ejemplo de coordinación unitaria. Los testimonios presentados son muestra del abanico de actores y luchas sociales de la época, entre ellos, el Comité de Unidad Campesina (CUC), los catequistas y delegados de la palabra de la teología de la liberación, las radios comunitarias, los sindicalistas, el Comité Pro Justicia y Paz, la Iglesia Guatemalteca en el Exilio, los campesinos indígenas refugiados en México, escritores, académicos y familiares de víctimas de asesinados y desaparecidos. Estos actores sociales tenían experiencia de lucha y liderazgo, y fueron financiados por organizaciones no gubernamentales (ONG) internacionales para ir a Madrid a dar su testimonio.

La "Sentencia del Tribunal Permanente de los Pueblos, Sesión sobre Guatemala”, de 26 páginas, condenó "las torturas, matanzas y las desapariciones forzadas" y calificó las matanzas y el terror contra "las etnias indias" como genocidio, ${ }^{9}$ con base en la Convención Internacional de la ONU, de 1948. La sentencia concluye:

El Tribunal declara que, ante la perpetración de los crímenes antedichos por parte de los poderes públicos de Guatemala, el pueblo de Guatemala tiene derecho a ejercer todas las formas de resistencia, incluso la fuerza armada, a través de sus organizaciones representativas, contra los poderes públicos tiránicos; y que el uso de la fuerza armada por parte del Gobierno de Guatemala para reprimir la resistencia es ilegítimo (TPP, 1984: 401).

Esta sentencia contundente es ilustrativa de una época muy diferente a los tiempos actuales de globalización neoliberal y pone de relieve los aires combativos de esos años, que permeaban a académicos, jurídicos, políticos y hasta sectores de las Iglesias, en su vertiente de teología de la liberación. Se basa en la "Declaración Universal de los Derechos de los Pueblos" o "Carta de Argel” (1976), ${ }^{10}$ que reivindica la autodeterminación de los pueblos y el derecho internacional vigente. La sentencia fue muy difundida y ayudó a legitimar el trabajo de denuncia, incidencia y cabildeo en ámbitos internacionales, entre ellos, la Asamblea General de las Naciones Unidas:

El TPP fue muy importante, en particular para coadyuvar a la unidad de las fuerzas revolucionarias guatemaltecas (FAR, EGP, PGT y ORPA), integradas en la URNG apenas en 1982, así como para dar visibilidad internacional a los diversos cuadros de la Oposición Guatemalteca en el trabajo internacional. Fue importante también para desgastar a Ríos Montt, particularmente frente a Estados Unidos, lo que permitió que en agosto de 1983 fuera removido. No obstante, hay que reconocer que, debido a la dinámica del proceso revolucionario y de la situación

9 Esto cobra especial importancia porque durante el juicio al general Ríos Montt, en este milenio, se desató un debate público feroz acerca de la existencia o no de genocidio en Guatemala durante el conflicto armado y el término se convirtió en un tema de discordia nacional.

10 Esta declaración, emitida por organizaciones y figuras públicas en torno a los procesos de liberación nacional del colonialismo en África, fue adoptada por la Fundación Leilo Basso, los TPP y la CDHG. En el caso de Guatemala, esto implicaba legitimar el levantarse en armas para la transformación social y el bienestar de la vasta mayoría empobrecida de la población guatemalteca. 
nacional de Guatemala, se desperdició mucho de lo producido en el propio tribunal. Incluso, la demora en la publicación de las versiones de la Memoria en castellano e inglés impidió que su distribución llegara en el momento más propicio. Hubo consecuencias más a largo plazo, como la receptividad europea a los planteamientos de la Oposición Guatemalteca (URNG y RUOG), que se evidenciaría en la ONU, y el apoyo de personalidades y ONG a la candidatura al Premio Nobel de la Paz de Rigoberta Menchú Tum en 1992 (Raúl Molina, correspondencia personal, 9 de julio de 2018).

Veamos algunos de los testimonios presentados por protagonistas mayas en el TPP.

\section{Testimonios de hombres y mujeres mayas en el TPP}

Antes del TPP, terceros atestiguaban acerca de las atrocidades cometidas hacia comunidades mayas. La revista Polémica tradujo y publicó un capítulo del informe Testigos de la violencia política en Guatemala, de los antropólogos Shelton H. Davis y Julie Hodson, de Oxfam América, ciudadanos estadounidenses que vivían y trabajaban en comunidades indígenas en Guatemala. El texto intentaba sensibilizar a sus compatriotas y destacar el papel del gobierno de su país a partir de su capital social como estadounidenses. Resalta la vida cotidiana de las comunidades indígenas bajo el asedio de políticas contrainsurgentes del Estado, en la que se contextualiza la extrema violencia. Un misionero protestante cuenta:

El Ejército secuestraba a cualquier persona (especialmente a los indígenas) que viajaba mucho... Un viejo de origen maya frecuentemente iba a las montañas cercanas, en busca de soledad, y para adorar a sus viejos dioses [sic]. Por alejarse de la aldea, se sospechó que estaba en contacto con las fuerzas guerrilleras, y fue secuestrado por la tropa, al volver de las montañas. El secuestro fue presenciado por otros vecinos de la aldea, y el cuerpo del anciano apareció lleno de balazos. Días después, el Ejército secuestró a sus dos hijos, los interrogó y fueron llevados al centro del pueblo, donde un oficial les dio muerte (Davis y Hodson, 1982: 62).

El tratamiento antropológico de estos textos ilustra la vida cotidiana en tiempos de guerra. Las diferencias entre las percepciones de los siete testigos estadounidenses revelan varios grados de inmersión y comprensión política del contexto guatemalteco y de la cultura de las comunidades mayas. Todavía no se había publicado el primer trabajo exhaustivo sobre una masacre, del antropólogo y sacerdote jesuita Ricardo Falla, basado en los testimonios de sobrevivientes refugiados en México, Masacre de la finca San Francisco (1983).

En este contexto, lo llamativo del TPP es que los testimonios son de actores político-sociales, en este caso, hombres y mujeres mayas. Gabriel Ixmatá asevera: "fue como una puerta que se abrió para nosotros como mayas" (entrevista, 26 de febrero de 2018). Por razones de espacio, es imposible analizar a fondo o incluir a los siete hombres y dos mujeres mayas que dieron su testimonio en el TPP. Escogí los testimonios por sus aportes y porque conozco a sus autores y pude dialogar con ellos, excepto una. No incluí el testimonio de Rigoberta Menchú por la extensa literatura que existe sobre ella, para abrir el espacio a las intervenciones elocuentes de otros testigos mayas. Vale señalar que en la controversia entre David Stoll ${ }^{11}$

En su libro Rigoberta Menchú y la historia de todos los guatemaltecos pobres, David Stoll (2002) se dedica a cuestionarla sobre la veracidad de su testimonio y muestra "pruebas" para desmentir que ella había vivido ciertas experiencias, como trabajar en las fincas, o que había presenciado la muerte de su hermano. El libro desató una gran polémica respecto a la narración individual o colectiva, el tratamiento metodológico y epistemológico de Menchú y el positivismo de Stoll. 
y Rigoberta Menchú (Beverley y Achugar, 2002; Arias, 2001, entre otros), ampliamente analizada, Beverley concluye: "lo que parece preocupar a Stoll es que Menchú no se limita a ser un 'informante nativo' que se prestaría a su deseo como antropólogo de observación e interpretación, sino que asume la autoridad, y la responsabilidad, de narrar su propia historia a través de un interlocutor letrado" (2002: 10).

Varios testigos mayas habían huido a comienzos de la década de 1980 y se habían refugiado en la Ciudad de México principalmente, donde operaban varias organizaciones guatemaltecas campesinas, de derechos humanos, agencias de prensa, de investigación, organizaciones sociales y humanitarias, ante la cerrazón de espacios en Guatemala. ${ }^{12}$ Después del TPP, algunos de los testigos citados aquí adquirieron perfiles más altos que otros en el campo de la denuncia internacional. Unos volvieron a Guatemala y se convirtieron en figuras públicas, como Rigoberta Menchú en su calidad de premio Nobel y candidata a la presidencia, y Pablo Ceto, quien fue diputado nacional. Otros dejaron la vida pública, se quedaron en México o se fueron a otro país. ${ }^{13}$

Una de las primeras personas mayas que habló en espacios públicos en varios países fue la catequista maya achi' de Rabinal, Carmelita Santos, ${ }^{14}$ del Comité Pro Justicia y Paz, una organización de acompañamiento y derechos humanos fundada en Guatemala en 1978, que se trasladó al exilio. Su testimonio de viva voz fue el primero que escuché de un sobreviviente maya, en un evento organizado por la Federación de Familiares de Detenidos Desaparecidos (Fedefam), en noviembre de 1983. Me impactó sobremanera. Todavía me acompañan sus palabras: “¿pero por qué nos están matando así, como chuchos [perros]?”.

Como integrante de Justicia y Paz, Carmelita Santos había viajado a Alemania y España, en octubre de 1982, para hacer trabajo de incidencia. Aún se puede encontrar en internet un artículo publicado en el diario El País, titulado "Una delegación maya denuncia el genocidio de Guatemala" (Mate, 1982). Es notable que el periodista Reyes Mate y la catequista se refieran al genocidio, que hablen de los mayas - poco común en aquella época-y que Carmelita también hable del etnocidio. El hilo conductor que atraviesa los testimonios de la catequista achi' y otros mayas, como Gabriel Ixmatá, es el reclamo por la negación de su calidad humana: "los soldados empezaron matando a los señores, porque dicen que los indios somos pícaros. Pero nosotros somos personas porque tenemos el mismo espíritu y sentimos el mismo dolor” (Mate, 1982). También habla en voz colectiva, el "nosotros maya": "quiero hablar en nombre de todos los hombres, mujeres, niños y ancianos de mi pueblo, para que se conozca en el mundo la gran injusticia que sufrimos allá y para que se reconozca el derecho que tenemos de vivir en la tierra como personas y como hijos de Dios" (тPР, 1984: 278).

Carmelita Santos ilustra la aseveración de Yúdice (2002: 240) sobre la función más importante del testimonio, de crear vínculos de solidaridad —añadiría de humanidad- entre pueblos. La

12 Durante varios años, organizaciones abiertas no podían operar en Guatemala, ni siquiera de derechos humanos. El primero en romper el silencio, en junio de 1984, fue el Grupo de Apoyo Mutuo (GAM), de familiares de detenidos-desaparecidos.

13 Este párrafo es impreciso con toda la intención, por respeto a la privacidad de los testigos. Aunque los acuerdos de paz se firmaron hace más de 20 años, todavía existe miedo entre muchos actores sociales de la época, incluyendo algunos aquí citados, que prefieren no dar a conocer su ubicación geográfica, actividades o nombres verdaderos. Esta psicosis del miedo no es infundada, pues sigue habiendo colaboradores locales del ejército que buscan hacer daño a personas específicas que hicieron denuncias públicas de las atrocidades cometidas por militares o que participaron en alguna de las organizaciones revolucionarias.

14 Intenté hablar con Carmelita Santos, pero no contestó mis llamadas. Es posible que temiera contestar una llamada de un número desconocido, por la práctica común de extorsiones vía telefónica. Dejé de insistir. 


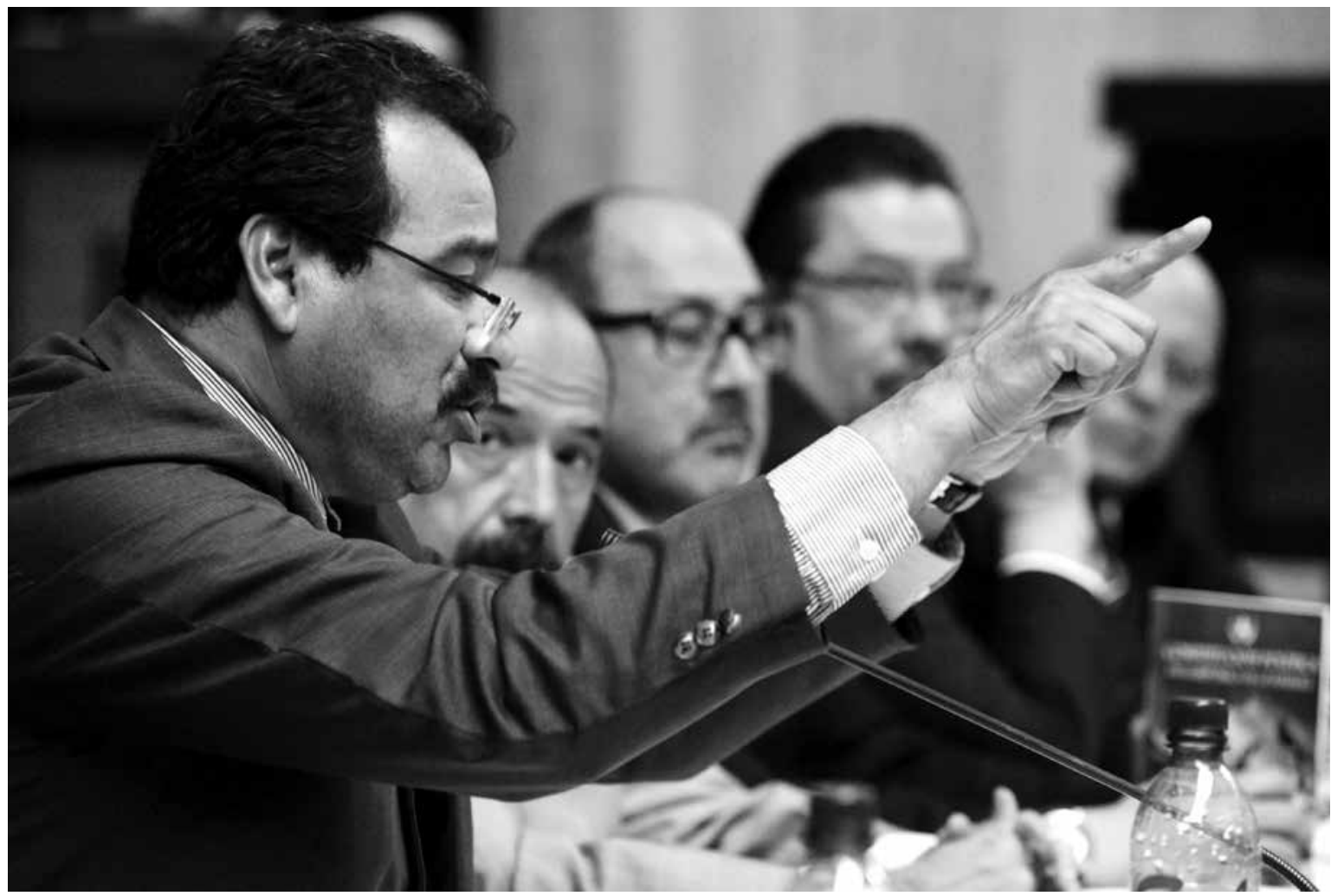

RICARDO RAmíREZ ARRIOLA $/ 360^{\circ}$ • Abogados defensores del ex general y ex dictador Efraín Ríos Montt en el juicio en su contra por genocidio y crímenes de lesa humanidad. Torre de Tribunales, Ciudad de Guatemala, Guatemala, 18 de abril de 2013.

revista Polémica publicó en 1983 el testimonio completo, de 11 páginas, que Santos entregó al TPP, pero en el libro sólo se incluyeron cinco páginas. Es interesante identificar las partes omitidas. Por ejemplo, la siguiente sección quedó fuera y no es claro si fue en aras de suavizar el tema del racismo o por el uso de calificativos, que denota indignación y rabia:

Nos han tratado en Guatemala como los indios tontos. No es así. Pues nosotros tenemos las mismas capacidades pero no tenemos la oportunidad de estudiar. Nos dicen que los indígenas no valemos y que hacemos mucho estorbo para Guatemala... Gritan los soldados, “ ¡indios mierdas! ¡Indios feos, patudos! ¡Mierda les haremos, huecos, pisados! ¡Indios putas!” y se ríen: “¡Ja, ja, ja!” (Santos, 1983: 80).
Esta omisión en el libro del TPP apunta al tema del papel del autor o editor al transcribir, recortar o seleccionar las partes de los testimonios. También es mi caso en este artículo, cuando escojo qué párrafos citar. En palabras de Ruth Bejar (1993), se convierten en "testimonios traducidos". Aunque los testimonios de mayas en el TPP constituyen una manifestación clara de autoexpresión, hay una interferencia — si no censura- implícita en los procesos de síntesis y selección.

Otra forma de crear silencios y constreñimientos hacia algunos testimoniantes, según me contaron en las entrevistas para este artículo, fue que su organización dictara el tema a atestiguar. Esto pasó con José Mendoza Ramírez y Gabriel Ixmatá. Con el primero no había problema, pues ambas partes — organización 
y testigo- coincidieron en la experiencia a comunicar: el caso de la radio Voz de Atitlán y la represión en Santiago Atitlán. En cambio, Gabriel Ixmatá recibió la instrucción de hablar sobre las condiciones infrahumanas en las fincas, porque las había sufrido en persona. Es interesante comparar su escueto testimonio en el TPP con la riqueza de su escrito en la revista Polémica, que no sólo habla de la explotación y el trato inhumano y racista en las fincas, sino que reflexiona sobre la cultura maya, los nawales, y defiende el alzamiento en armas contra el sistema opresivo. Explica que se trata de un proceso histórico de resistencia y rebelión: "nuestra lucha no es una lucha que hasta ahora empieza, sino que es una lucha que ya tiene años, ${ }^{15}$ y que hay que terminar con la actitud que se ha tenido con nosotros" (Ixmatá, 1983: 40).

Al comienzo del artículo, Polémica señala: "este documento fue escrito originalmente en idioma mam” (Ixmatá, 1983: 32). Me parecía poco probable y le pregunté a Gabriel. Dijo que en efecto había entregado un escrito en maya-mam, ${ }^{16}$ que un sacerdote español que hablaba mam lo había traducido y se había complementado con una entrevista que le hizo Polémica antes de publicar su artículo (conversación con Gabriel Ixmatá, 27 de marzo de 2018). Sin embargo, nunca le dieron el borrador para hacer sus propias correcciones. Apenas lo vio cuando se publicó. Esto aún le provoca rabia, pues se usa la palabra "naturalista" (Ixmatá, 1983: 35) para aludir a los indígenas, cuando Gabriel usa el término "naturales" para referirse a la conexión colectiva de los pueblos indígenas con la naturaleza. Esto se vincula con su historia de largo aliento:

Tenemos una historia, tenemos nuestros antepasados; nosotros no somos un pueblo que es traído de un lugar y puesto o impuesto en Guatemala... No nos han tirado con honda, pues: a nosotros no nos tiraron de por allá lejos, para venir a caer en un lugar. Nosotros tenemos nuestras raíces, nuestros antepasados (Ixmatá, 1983: 35).
A pesar de las buenas intenciones del editor del artículo, se manifiesta un poder naturalizado, una falta de respeto al no buscar el visto bueno del autor indígena, lo que levanta cuestionamientos sobre las medidas que deben tomarse a la hora de citar las palabras de los testimoniantes.

En cambio, la experiencia de dar testimonio sobre la radio Voz de Atitlán fue más fluida. José Mendoza escribió su texto y aceptó la corrección de estilo para que mejorara. Pidió usar seudónimo para no poner en riesgo a sus familiares, que permanecían en Santiago Atitlán, y formó parte del grupo de unas cinco personas que dieron su testimonio detrás de una cortina o velo durante la sesión del TPP. Estos detalles demuestran su agencia social y el trato respetuoso que recibió en los momentos de preparación y presentación de su doloroso testimonio. Habló de la creación y comienzos, en 1966, de la radio comunitaria, así como del papel de la emisora hasta hoy, a pesar de la represión a sus valiosos integrantes:

Teníamos una emisora para transmitir los programas para todos los pueblos vecinos. Participaban niños, jóvenes, señoras, ancianos y hermanos y pueblos vecinos; compartíamos nuestras penas, sufrimientos, así como nuestras alegrías. Todos los miembros de la Asociación trabajábamos voluntariamente a cambio de hallar la felicidad, el bienestar de la vida de nuestros pueblos humillados.

Al trabajar con gente maya conocí una noción diferenciada del tiempo. "Una lucha que lleva años" se refiere por lo general al periodo de la Conquista o invasión hasta nuestros días.

16

Pude constatarlo en 2018, cuando ayudé a Gabriel a digitalizar los relatos que había escrito sobre las prácticas y cultura mam. No entendía por qué a veces se quedaban en silencio cuando me dictaba, hasta que caí en la cuenta de que lo escrito en su cuaderno estaba en mam. Uno de sus relatos fue publicado en la revista Viernes (2018). 
Cuando tratamos de salir de la miseria, el odio de los Gobiernos y los ricos terratenientes luego nos destruyen (TPP, 1984: 248).

Así empezó la represión política a la radio:

En mayo, un grupo de soldados vestidos de ropas típicas del lugar hicieron disparos dentro de la población, dejando a dos mujeres y dos niños heridos. Nuevamente en junio con ropa típica entraron a asesinar a dos mujeres ex miembros de la Asociación la Voz de Atitlán. Los paramilitares secuestran a un maestro indígena en la población, fue golpeado salvajemente (TPP, 1984: 249).

El testimonio de quien usó el seudónimo de José Mendoza destaca porque comparte con precisión quiénes fueron los perpetradores: distingue entre los paramilitares y los soldados, y la manera en la que éstos se visten, no como civiles, sino con ropa local, ${ }^{17}$ para tratar de esconder su identidad. A la vez, ilustra la resistencia de los tz'utujiles: "la población de Santiago Atitlán se organiza: por las noches dormían en las Iglesias evangélicas y católicas, familiares y vecinos se juntaban a dormir en una sola casa" (TPP, 1984: 249).

Este testimonio sobresale porque transmite al público la agencia social y resistencia de su pueblo, en combinación con la denuncia de las agresiones de los perpetradores. En conversación telefónica del 14 de julio de 2018, José Mendoza relató que su participación en el TPP no fue su primer viaje al exterior, pues en su calidad de secretario ejecutivo había visitado otros países de Latinoamérica para reunirse con otras radios comunitarias, pero sí fue la primera vez que dio testimonio ante un público. Considera que el TPP abrió muchos espacios de contacto con grupos de solidaridad y universidades, a los que visitó después.

Por último, el testimonio de Pablo Ceto, maya ixil de Nebaj, es una rica narración que entrelaza la denuncia, la lucha y la cultura maya. En una conversación por WhatsApp, el 30 de junio de 2018, tres décadas después, reconoce y reafirma qué quiso expresar en su testimonio: "asumo mi responsabilidad, es lo que quería exponer”. Habla del racismo: "aprendí a leer y a escribir el alfabeto, como también la humillación y el desprecio; es decir, la discriminación a los indígenas" (TPP, 1984: 238). A veces, resalta la cultura maya: "hemos forjado modos de caminar, que tienen en el fondo, la vida comunitaria de nuestros pueblos, el espíritu de compartir no sólo las penas, sino la perspectiva de futuro. Hay ahí esencias y valores de la cultura de mis antepasados" (TPP, 1984: 239). Esto es interesante, en especial porque Pablo es reconocido como una figura pública del Ejército Guerrillero de los Pobres (EGP) y la URNG. Habla de esa vida comunitaria y de la perspectiva indígena de futuro.

Lo más destacado del testimonio es el largo y diverso proceso de lucha social. Su voz de lucha va acompañada de indignación y denuncia: "sólo en su Gobierno [de Ríos Montt], son más de 10000 asesinados. Hay un millón de desplazados internos, hay millares de niños huérfanos, de mujeres viudas, y hay un hambre regada en montañas y barrancos, porque ha sido quemada nuestra siembra y cultivo, nuestros ranchos y bienes. Y aún más, quemados nuestros bosques” (TPP, 1984: 139). Aquí no sólo está la denuncia de la violencia atroz hacia los seres humanos, sino también hacia la naturaleza, por ende, hacia la cultura maya, elementos esenciales de las cosmovisiones indígenas que se traslucen en el testimonio.

El TPP es un hito en el espacio y presencia de las voces y testimonios de mujeres y hombres mayas en el mundo. En este mismo periodo se publicó el libro Me llamo Rigoberta Menchú y así me nació la

Santiago Atitlán es de los pocos lugares en el altiplano guatemalteco en el que los hombres todavía usan su traje. 
conciencia (Burgos, 1983) y tuvieron lugar eventos organizados por la solidaridad internacional con participación de personas mayas e integrantes del Comité Pro Justicia y Paz y el Cuc. Poco después surgió el Equipo de Trabajo Indígena, vinculado a la URNG, y agrupaciones relacionadas con alguna organización revolucionaria fuera y dentro de Guatemala, unas más cercanas y otras más autónomas. En el exterior sobresalen el Taller Ja C'amabal I'B, en México, y la Liga Maya, en Costa Rica y Estados Unidos, creados en 1989. Dentro de Guatemala despuntan la Coordinadora Nacional de Viudas de Guatemala (Conavigua), de 1988, y Majawil Q'ij, de 1990, entre otras. Todas hacen trabajo internacional y presentan testimonios que combinan la denuncia de la represión política, la apelación a la solidaridad internacional y la cultura maya. El TPP detonó la emergencia en el ámbito internacional de actores mayas cercanos a las organizaciones revolucionarias.

\section{Reflexiones finales}

En este artículo he explorado el poco analizado tema de los testimonios producidos durante contextos de guerra, en este caso, en un tribunal de conciencia durante el conflicto armado en Guatemala. Sin embargo, aunque existen y han sido recogidos y analizados por Stephen (2017) y De Marinis (2013), entre otros, el proceso de teorización es aún incipiente, a diferencia de los muy estudiados testimonios que forman parte de la justicia transicional, los estudios de la memoria y los testimonios-libros heroicos. Un rasgo clave de estos testimonios es que están marcados por la urgencia del momento: son un llamado desesperado a que se ponga fin a una situación casi innombrable de horror, literalmente de vida o muerte; manifiestan una potente urgencia política porque comunican el sentir y el horror de lo que sucede — ya sean los poemas de Owen en la Primera
Guerra Mundial o las intervenciones emotivas ante un público empático-, con el objetivo de crear conciencia y acabar con las atrocidades. Se diferencian de otros testimonios por su espontaneidad, porque no tienen filtros o formas de rememorar que adecuen los significados a la experiencia actual. Por lo regular, gozan de mayor libertad para hablar de las luchas sociales e insurgentes, y de prácticas culturales mayas, como en este caso. Con el tiempo, la inmediatez y urgencia de estos testimonios ceden a formas más elaboradas y discursos más armados, incluso durante los procesos bélicos.

Los testimonios mayas analizados son diversos. Unos se centran en la denuncia y el horror. Otros ponen énfasis en el contexto de lucha armada y rebelión, reivindican el derecho de combatir al Estado y el sistema excluyente. Algunos hablan de la cultura maya y el racismo estructural, se salen del guión de denuncia esperado. El TPP fue un evento trascendental en su época porque dio a conocer las atrocidades que sucedían en ese momento en Guatemala. Abrió un espacio para escuchar en directo a testimoniantes mayas: "sentimos que fuimos escuchados por primera vez" (entrevista con Gabriel Ixmatá, 26 de febrero de 2018). Su participación en el TPP abrió puertas para la representación maya en espacios internacionales, entre ellos, la ONU. Para Gabriel, significó "un punto y aparte" en términos de autorrepresentación como mayas.

Aun así, hemos visto que algunos de los testimonios emitidos durante los sucesos pasan por filtros y silenciamientos, sobre todo a la hora de plasmarlos por escrito y publicarlos. En el caso de actores políticos mayas históricamente sin voz, son terceros - los editores - quienes deciden qué incluir, qué descartar o incluso qué añadir o modificar. Se reinscribe así cierta falta de control sobre la manera de autorrepresentarse. Cuando envié a Pablo Ceto su testimonio en el libro del TPP, se sorprendió de que sólo fueran tres páginas. Al comparar el testimonio de Carmelita Santos en el libro del TPP con el que 


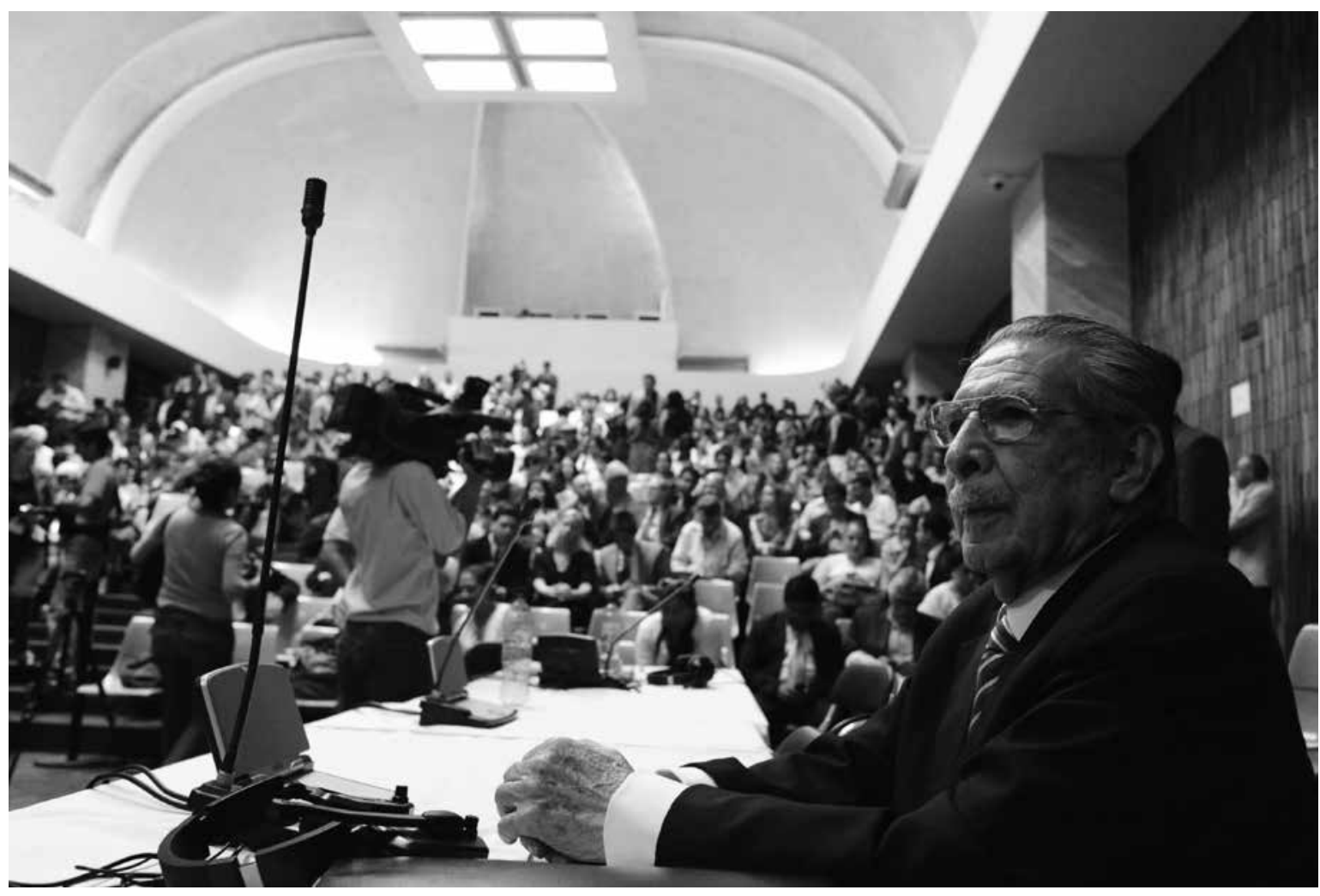

RicARdo Ramírez ARriola/360 Efraín Ríos Montt, en el juicio en su contra, acusado de genocidio y crímenes de lesa humanidad. Torre de Tribunales, Ciudad de Guatemala, Guatemala, 18 de abril de 2013.

publicó Polémica, entendí el desconcierto de Ceto. Para evitar esta forma de extractivismo, envié a cada uno lo que escribí. ${ }^{18}$ Esta consulta me obligó a cambiar varias cosas, en un intercambio con testigos que también cuestionan y se apropian del tema para dar lugar a un ejercicio necesario, laborioso y a veces incómodo.

El TPP abrió un espacio para la denuncia de atrocidades que habían recibido poca atención internacional. El jurado, el Comité de Honor y el público se convirtieron en testigos secundarios (Laub, 1992; Wake, 2008) al empatizar con los testigos, pues por la naturaleza de un tribunal de conciencia no suelen participar escépticos. Se convirtió en un punto de inflexión que hizo llegar las denuncias al ámbito internacional mientras las masacres seguían sucediendo en Guatemala.
A pesar de la trascendencia del TPP Sesión Guatemala en su momento, éste ha caído en el olvido. El libro tuvo una circulación limitada y la sentencia, aunque está en Internet, está descontextualizada. Para alguien que no vivió en esa época es difícil dimensionar su importancia e impacto en su momento. La sentencia del TPP condenó el genocidio en Guatemala décadas antes del juicio a Ríos Montt en 2014. Al no ser filmado y colocado en internet, no se transmitió la emotividad, solemnidad y contundencia de la condena al gobierno de Ríos Montt por genocidio.

Salvo Carmelita Santos, por las razones señaladas en la nota 15. 
Los testimonios emitidos durante los sucesos no están sometidos a los constreñimientos de la justicia transicional, que tiene pautas normativas y un carácter institucionalizado, fija lo que se puede o no decir, y enfatiza la calidad de víctima y no de protagonista. Castillejo (2007: 78) critica que las comisiones de verdad y reconciliación (CVR) dejan fuera problemas fundamentales, como el despojo masivo de tierras en Sudáfrica, e imponen un "topos de la enunciación”. El informe de la CVR en Perú habla de los "terroristas" y clausura así la posibilidad de salir del guión de víctima (Rodríguez, 2011), lo que impide entender las causas del conflicto y la agencia de los actores sociales.

Estos testimonios se caracterizan por una mayor libertad de expresión y agencia social que las CVR, aunque su naturaleza también responde al tipo de foro en el que se presentan, que no se puede generalizar. Hay matices entre los tribunales de conciencia, foros de Fedefam, revistas y diarios. El TPP sobre Guatemala abrió un espacio políticamente radical para los testimonios mayas durante el conflicto armado interno, al abarcar no sólo la denuncia de la represión, sino la crítica al capitalismo y el imperialismo. La libertad de expresión se percibe en la amplitud y diversidad del campo de denuncia, y la apelación a la lucha expresa los reclamos y reivindicaciones de los testimoniantes, aunque en algunos casos hay constricciones impuestas por sus organizaciones y los editores de las publicaciones.
El TPP habló de la violencia estructural - la sobreexplotación, la extrema pobreza, la exclusión y el racismo- ${ }^{19}$ y reivindicó la cultura maya y el derecho a la rebelión. Al basarse en la "Carta de Argel” y el derecho a la autodeterminación, afirmó la legitimidad del derecho a la lucha armada. Los testimonios se acoplan a esta radicalidad, se percibe en ellos la concientización de la que habla Yúdice (2002) y la influencia de Freire y la teología de la liberación. Así, estos testimonios no pueden comprenderse si se extraen de su contexto específico. Los que analizamos aquí pertenecen a una época y un foro específicos, que les imprimen ciertas características.

Los organizadores del TPP y el jurado, aún en su diversidad, eran representativos de una época en la que imperaban voces progresistas, incluso revolucionarias, de la intelectualidad de izquierda, el ala radical de las Iglesias y profesionales de renombre. Reflejan un momento histórico revolucionario que fue disminuyendo con la caída del muro de Berlín, la coartación de la teología de la liberación y el surgimiento del neoliberalismo. D

El TPP no retomó la violación sexual como arma de guerra en su sentencia, a pesar de los testimonios que la mencionaron.

\section{Bibliografía}

Acedo Alonso, Noemí, 2017, “El género testimonio en Latinoamérica: aproximaciones críticas en busca de su definición, genealogía y taxonomía”, en Latinoamérica, núm. 64, pp. 39-69.

Achugar, Hugo, 2002, "Historias paralelas/historias ejemplares: la historia y la voz del otro", en John Beverley y Hugo Achugar (coords.), La voz del otro: testimonio, subalternidad y verdad narrativa, Universidad Rafael Landívar, Guatemala, pp. 61-83.

Agamben, Giorgio, 2000, "El testigo", en Lo que queda de Auschwitz. El archivo y el testigo. Homo Sacer III, Pre-Textos, Valencia, pp. 8-21. Arendt, Hannah, 1970, Sobre la violencia, Alianza, Madrid.

-, 2013, Eichmann en Jerusalén. Un estudio de la banalidad del mal, Lumen, Barcelona.

Arias, Arturo, 2001, The Rigoberta Menchú Controversy, University of Minnesota Press, Minneapolis.

Bejar, Ruth, 1993, Translated Woman: Crossing the Border with Esperanza's Story, Beacon Press, Boston. 
Beverley, John, 2002a, “Prólogo a la segunda edición”, en John Beverley y Hugo Achugar (coords.), La voz del otro: testimonio, subalternidad y verdad narrativa, Universidad Rafael Landivar, Guatemala, pp. 9-16.

—_, 2002b, "Introducción”, en John Beverley y Hugo Achugar (coords.), La voz del otro: testimonio, subalternidad y verdad narrativa, Universidad Rafael Landívar, Guatemala, pp. 17-29.

Beverley, John y Hugo Achugar (coords.), 2002, La voz del otro: testimonio, subalternidad y verdad narrativa, Universidad Rafael Landívar, Guatemala.

Burgos, Elizabeth, 1983, Me llamo Rigoberta Menchú y asi me nació la conciencia, Casa de las Américas, La Habana.

Calveiro, Pilar, 2006, "Testimonio y memoria en el relato histórico", en Acta Poética, vol. 27, núm. 2, pp. 65-86.

Castillejo Cuéllar, Alejandro, 2005, "Las texturas del silencio: violencia, memoria y los límites del quehacer antropológico”, en Empiria, núm. 9, pp. 39-59.

—_ 2007, “La globalización del testimonio: historia, silencio endémico y los usos de la palabra”, en Antípoda, núm. 4, pp. 75-99.

“La carta de Argel. Declaración Universal de los Derechos de los Pueblos. Argel, 4 de julio de 1976", 1976. Disponible en línea: <http://perma nentpeoplestribunal.org/wp-content/uploads/2016/06/CARTA-DE-ARGEL-ES.pdf>. Consultado el 15 de marzo de 2019.

Comisión para el Esclarecimiento Histórico (CEH), 1999a, Guatemala, memoria del silencio, Oficina de Servicios para Proyectos de las Naciones Unidas, Guatemala.

_ Unidas, Guatemala.

Davis, Shelton H. y Julie Hodson, 1982, "Voces de los testigos", en Polémica, núm. 6: Testigos de la violencia política en Guatemala de Oxfam América, pp. 59-69.

Falla, Ricardo, 1983, Masacre de la finca San Francisco, Huehuetenango, Guatemala (17 de julio de 1982), International Work Group for Indigenous Affairs, Copenhague.

Felman, Shoshana, 2000, "Theaters of Justice: Arendt in Jerusalem, the Eichmann Trial, and the Redefinition of Legal Meaning in the Wake of the Holocaust", en Theoretical Inquiries in Law, vol. 1, núm. 2, pp. 465-507.

Franco, Jean, 2002, "Si me permiten hablar: la lucha por el poder interpretativo", en John Beverley y Hugo Achugar (coords.), La voz del otro: testimonio, subalternidad y verdad narrativa, Universidad Rafael Landivar, Guatemala, pp. 121-127.

Givoni, Michal, 2011, "Witnessing/Testimony”, en Mafte’akh, núm. 2, pp. 147-169.

Hobsbawm, Eric, 1998, "La historia de la identidad no es suficiente”, en Eric Hobsbawm, Sobre la historia crítica, Crítica, Barcelona, pp. $266-276$.

International Committee of the Red Cross (ICRC), 2005, "ICRC in wwI: Overview of Activities", 11 de enero. Disponible en línea: <https://www. icrc.org/eng/resources/documents/misc/57jggq.htm>.

Ixmatá, Gabriel, 1983, "Con nuestra propia voz", en Polémica, núms. 10-11, pp. 32-40.

Jelin, Elizabeth, 2002, Los trabajos de la memoria, Siglo XXI Editores, Madrid.

Laub, Dori, 1992, "Bearing Witness or the Vicissitudes of Listening", en Shoshana Felman y Dori Laub, Testimony. Crises of Witnessing in Literature, Psychoanalysis, and History, Routledge, Nueva York, pp. 57-74.

Levi, Primo, 1989, Se questo é un uomo, Einaudi, Turín.

__, 2004, "The Gray Zone”, en Nancy Scheper-Hughes y Philippe Bourgois (eds.), Violence in War and Peace, Blackwell, Malden, pp. 83-90.

Manfredi, Zachary, 2018, "Sharpening the Vigilance of the World: Reconsidering the Russell Tribunal as Ritual”, en Humanity, vol. 9, núm. 1, pp. 75-91.

Marinis, Natalia de, 2013, En los márgenes de la (in)seguridad: desplazamiento forzado y relaciones de género y poder en San Juan Copala, Oaxaca, tesis de doctorado en antropología social, Centro de Investigaciones y Estudios Superiores en Antropología Social, México.

Mate, Reyes, 1982, “Una delegación maya denuncia el genocidio de Guatemala”, en El País, 5 de octubre. Disponible en línea: <http://elpais. com/diario/1982/10/05/internacional/402620415_850215.html>.

Pollak, Michael, 2006, Memoria, olvido, silencio. La producción social de identidades frente a situaciones límite, Al Margen, La Plata.

Portelli, Alessandro, 1989, "Historia y memoria: la muerte de Luigi Trastulli”, en Historia y Fuente Oral, núm. 1, pp. 5-32.

Remarque, Erich Maria, 1929, Sin novedad en el frente, Editorial España, Madrid.

Reyes Prado, Anantonia y Ruth del Valle, 2013, “Defensa y promoción de los derechos humanos en Guatemala”, en Virgilio Álvarez Aragón, Carlos Figueroa Ibarra, Arturo Taracena Arriola, Sergio Tischler Visquerra y Edmundo Urrutia García (eds.), Guatemala historia reciente (1954-1996), t. IV: Proceso de paz y contexto internacional, Facultad Latinoamericana de Ciencias Sociales-Guatemala, Guatemala, pp. 257-335. 
Ridao, José Miguel, 2012, "Wilfred Owen: Anthem for Doomed Youth", en Por Estos Andurriales, 9 de agosto. Disponible en línea: <http:// jmridao.blogspot.com/2012/08/wilfred-owen-anthem-for-doomed-youth.html>.

Rodríguez Maeso, Silvia, 2011, "Testimonios, discurso experto y comisiones de la verdad: el contexto de la denuncia”, en Política y Sociedad, vol. 48, núm. 3, pp. 587-602.

Santos, Carmelita, 1983, “Testimonio de Carmelita Santos”, en Polémica, núms. 7-8, pp. 77-87.

Scheper-Hughes, Nancy y Philippe Bourgois (eds.), 2004, Violence in War and Peace, Blackwell, Malden.

Stephen, Lynn, 2015, "Martin Diskin Memorial Lecture, San Juan, Puerto Rico, 29 de mayo de 2015. Ser testigo presencial. Acompañando, presenciando, actuando", en Forum, vol. XLVI, núm. 3, pp. 4-14.

_ Caribbean Anthropology, vol. 22, núm. 1, pp. 85-109.

Stern, Steve, 2000, "De la memoria suelta a la memoria emblemática: hacia el recordar y el olvidar como proceso histórico (Chile, 1973-1998)", en Mario Garcés (comp.), Memoria para un nuevo sig/o. Chile, miradas a la segunda mitad del siglo xx, LOM/Eco Educación y Comunicaciones/Universidad de Santiago de Chile, Santiago, pp. 11-33.

Stoll, David, 2002, Rigoberta Menchú y la historia de todos los guatemaltecos pobres, Consucultura, Guatemala.

Traverso, Enzo, 2016, “Memoria e historial del siglo xx”, en María Graciela Acuña, Patricia Flier, Myrian González, Bruno Groppo, Evelyn Hevia, Loreto López, Nancy Nicholls, Alejandra Oberti, Claudia Bacci, Susana Skura y Enzo Traverso, Archivos y memoria de la represión en América Latina (1973-1990), LOM/Fundación de Ayuda Social de las Iglesias Cristianas, Santiago, pp. 17-29.

Tribunal Permanente de los Pueblos (TPP), 1984, Sesión Guatemala, Madrid, 27-31 de enero de 1983, Instituto de Estudios Políticos para América Latina/África Editorial, Madrid.

Viernes, 2018, año 5, núm. 217. Disponible en línea: <https://issuu.com/_dca/docs/edicio_n_217_revista_viernes_26012>.

Wake, Caroline, 2008, "Through the (In)visible Witness in Through the Wire", en The Journal of Applied Theatre and Performance, vol. 13, núm. 2. pp. 187-192.

Wieviorka, Annette, 2006, The Era of The Witness, Cornell University Press, Ithaca.

Yúdice, George, 2002, “Testimonio y concientización”, en John Beverley y Hugo Achugar (coords.), La voz del otro: testimonio, subalternidad y verdad narrativa, Universidad Rafael Landívar, Guatemala, pp. 221-242.

Zola, Émile, 1898, “J’accuse”, en L’Aurore, 13 de enero, París.

\section{Entrevista}

Gabriel Ixmatá, 26 de febrero de 2018. 